\title{
LA HERENCIA CORPORAL. MUERTE Y SALUBRIDAD EN EL REINO DE CÓRDOBA DURANTE LA EDAD MODERNA
}

\author{
Adolfo Hamer Flores \\ UNIVERSIDAD DE CóRdoba
}

\begin{abstract}
RESUMEN
Este trabajo intenta poner de manifiesto la importancia de la presencia física de la muerte durante el Antiguo Régimen. Asimismo, se analiza el universo ideológico del hombre moderno y el grado de difusión de las nuevas concepciones y corrientes. Para ilustrar estos aspectos se utiliza el caso del reino de Córdoba.
\end{abstract}

Palabras clave: cadáver, muerte, salubridad, Edad Moderna, Córdoba.

\section{ABSTRACT}

This article intends to make clear the importance of death's physical presence during the Old Regime. In like manner, we emphasize the Modern people's ideological universe and the extent to which the new concepts and ways of thinking. To exemplify these aspects, present work shows results for the case of Kingdom of Cordova.

Key words: body, death, healthiness, Modern Age, Cordova.

\section{INTRODUCCIÓN}

El espacio funeral comunitario así como la percepción de la muerte no se han caracterizado precisamente por permanecer inmutables a lo largo del tiempo ${ }^{1}$. Al contrario, han experimentado

\footnotetext{
El presente artículo se basa, en gran medida, en un trabajo realizado por el que suscribe estas líneas en el contexto del curso de Doctorado titulado "La vida cotidiana en la Córdoba del Siglo de Oro", impartido por el profesor Manuel Peña Díaz en la Universidad de Córdoba.
} 
diversas reformulaciones, las cuales constituyen, dicho sea de paso, testimonios interesantísimos acerca de las transformaciones sociales.

Así pues, la muerte, como elemento perteneciente a las estructuras mentales que es, ha estado sujeta a pertinaces inercias, pero también a continuas transformaciones impuestas por los vaivenes socioeconómicos y los cambios mentales, los condicionantes demográficos...

Nuestra intención aquí, por tanto, pasa por aproximarnos desde el punto de vista físico al mundo de la muerte en el periodo que va aproximadamente desde finales del siglo XV hasta comienzos del XIX. Una análisis que efectuaremos tanto a nivel general como valiéndonos, en la medida de lo posible, del ejemplo concreto del reino de Córdoba.

\section{CADÁ VERES Y VIDA COTIDIANA EN LA EDAD MODERNA}

Durante muchos siglos los muertos permanecieron alejados de los vivos, descansando en los cementerios ubicados fuera de las poblaciones. En este sentido, y a modo de ejemplo, la antigua ley romana de las Doce Tablas ya establecía que dentro del pomerium o recinto urbano ningún cadáver debía ser quemado ni enterrado.

Los primeros cristianos observaron también esta norma, que se iría alterando, no obstante, en una lenta evolución que abarcaría un milenio. Según Philippe Ariés, las tumbas de los mártires, con la protección que garantizaban a los que junto a ellas se enterraban, se convirtieron rápidamente en el lugar apetecido por los fieles para emplazar sus propias sepulturas; una dinámica a la que tampoco serían ajenos los intereses del clero ligado a estos espacios. De este modo, sobre las tumbas veneradas se erigieron martyria y después basílicas, algunas de las cuales acabarían siendo importantes abadías rodeadas de cementerios. Las ciudades pasarían a poseer dos centros de vida cristiana: la catedral, sede de la administración episcopal, y el santuario cementerial con las tumbas de santos y mártires, así como las de numerosos creyentes.

Paulatinamente, la distinción entre la ciudad y los arrabales donde se verificaban los entierros se fue difuminando, al igual que las diferencias funcionales entre los santuarios del interior y del exterior de las murallas. Con ello, en torno a las iglesias urbanas acabaron surgiendo cementerios propios: los muertos pasaban a compartir un mismo espacio con los vivos.

\subsection{Convivir con los muertos (siglos XVI y XVII)}

En la Edad Media, los cementerios eran lugares públicos, espacios de encuentro, de juegos... a pesar de la exhibición de huesos en los osarios y de los trozos de cadáveres que surgían mal cubiertos ${ }^{2}$. En este sentido, sabemos que, al menos hasta el siglo XVII, los huesos de los cadáveres afloraban incluso al suelo, mezclados con piedras y guijarros ${ }^{3}$. Un espectáculo que no despertaba entre los vivos más temor que la idea de su propia muerte. Tan familiares les eran los muertos como familiarizados estaban con su propia muerte ${ }^{4}$.

Un hecho que llevaba a que en un mismo espacio se diera la coexistencia de inhumaciones y de reuniones públicas, entre las que podemos citar ferias, bailes y juegos; todo en un grado de familiaridad que hoy se nos antojaría casi indecente ${ }^{5}$.

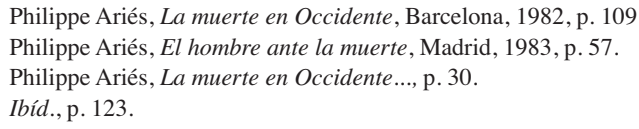


Viajeros y pobres solían quedarse a vivir en los cementerios por espacios prolongados; al igual que clérigos y laicos, cuyas viviendas alquiladas daban, en no pocas ocasiones, al interior de estos recintos. Es más, a veces también se administraba allí justicia, e incluso se solemnizaban actos notariales y privados ${ }^{6}$. Un fenómeno este último relacionado con el hecho de que muchos de los cementerios acabaron con el tiempo siendo porticados. Además, si tenemos en cuenta que la mayor parte de los pueblos carecían de casas consistoriales y de cualquier otro espacio público protegido de la lluvia, no nos debe extrañar que a ellos pasasen las reuniones de la comunidad, tanto cívicas como privadas?

Y este estado de ánimo medieval subsistió mucho tiempo en las capas populares. Así, hasta los siglos XVII y XVIII el cementerio de los Inocentes de París siguió siendo un lugar de encuentros y paseos $^{8}$. Igualmente, para el caso español, las constituciones sinodales de sus obispados elaboradas en los siglos XVI y XVII nos informan de numerosas prohibiciones que nos señalan que estos recintos eran escenario de profusas actividades. Sin duda, la más usual eran los juegos. Dieciséis constituciones aluden a la costumbre de jugar a los naipes en el cementerio, trece a la pelota, once a los bolos, ocho al herrón y al mojón, mencionándose en otras ocasiones los dados, la argolla, el tejo, la ballesta y ejercicios de esgrima, lucha o barra.

La prohibición de hacer bailes y danzas se encuentra en trece de las veintiocho sinodales analizadas por Martínez Gil. La reprobación de la celebración de concejos y de juicios la encontramos en diez y en dos de ellas, respectivamente. En cinco ocasiones el mandato es que no se hagan «conbites ni collaciones ni comidas de cofradias ni de mortuorios ni de bodas ni de missas nuevas ni otras solemnidades»; tres veces se prohíbe correr toros y una representar comedias el día del Corpus.

El cementerio transformado en mercado es el tema de cinco constituciones. Se mencionan negocios, ferias, mercados, carnicerías, pescaderías, tiendas de merceros y buhoneros. Incluso se denuncia el desarrollo de diversas actividades laborales en pleno cementerio. Otras prohibiciones tenían que ver con los caminos que cruzaban muchos cementerios, los bancos en que la gente se sentaba a hablar, el arrojo de inmundicias y la constante penetración de animales 9 .

Ahora bien, volviendo al proceso de invasión de las iglesias comenzado en la Edad Media, podemos apuntar que tuvo su culminación en la época barroca. Y ello fue posible por la gran cantidad de fundaciones de iglesias y monasterios, entre cuyas principales funciones se contaba sin duda la funeraria. Los privilegios que en siglos anteriores permitían el enterramiento dentro de las iglesias a determinadas personas fueron ampliándose a fuerza de no ser respetados y ya en el siglo XVI todo el mundo podía gozar de ellos si pagaba los derechos correspondientes ${ }^{10}$.

En principio, el motivo que empujó a la inhumación de los cadáveres dentro de las iglesias fue el de poder situarlos lo más cerca posible de los puntos más sagrados del templo, especialmente el altar mayor y los lugares en los que se ubicaban las reliquias de los santos. Se pensaba que ya dentro del templo, cuanto más próxima estuviese la tumba a los citados puntos, mayores serían los beneficios espirituales para los enterrados en ella. Como norma general se consideraban de más calidad las sepulturas que estuviesen más próximas al presbiterio y de peor cuanto más separadas de él.

Fernando MARTíNEZ GIL, Muerte y sociedad en la España de los Austrias, Madrid, 1993, p. 448.

Juan Madariaga Orbea, "Espacio doméstico y espacio sepulcral en Euskal Herria, siglos XVI al XIX”, en José María Imízcoz Beunza (ed.), Casa, familia y sociedad (País Vasco, España y América, siglos XV-XIX), Bilbao, 2004, p. 436.

Philippe Ariés, La muerte en Occidente..., p. 109.

Fernando MARTÍNEZ GIL, Muerte y sociedad en la ..., p. 450.

Fernando Martínez Gil, Muerte y sociedad en la..., pp. 435-436. 
En pleno proceso de tránsito de las inhumaciones cementeriales a las intraeclesiásticas, la justificación esgrimida por los parroquianos para probar la necesidad del mismo recurría substancialmente en los inconvenientes que derivaban de los sepelios al aire libre, con el riesgo de que entrasen los animales en el cementerio y desenterraran los cadáveres. Ahora bien, en la mayor parte de los casos esto era algo muy improbable, pero no por ello dejaba de ser un argumento de cierto peso ante el traslado de los enterramientos e incluso ante la necesidad de ampliar las iglesias para que pudieran albergar las inhumaciones de todos los vecinos ${ }^{11}$.

Por otro lado, en este cambio de las costumbres funerarias también influyó el reforzamiento teológico del Purgatorio, período de la vida ultraterrena en donde las penas por cumplir podían redimirse y reducirse mediante oraciones. Desde estas creencias se pensaba que los enterramientos en el interior de los templos hacían los sufragios mucho más efectivos ${ }^{12}$. El cementerio, por tanto, quedó para los pobres ${ }^{13}$.

Los autores religiosos también se mostraron proclives a ese proceso, no sólo por los supuestos beneficios espirituales que recibiría el alma del finado sino sobre todo por el aumento de hermandades, altares, capillas, institución de misas y sufragios,... que el traslado del lugar de entierro desde el cementerio a los templos conllevaba ${ }^{14}$.

Por este motivo, al menos hasta finales del siglo XVIII, las iglesias se mostraban completamente pavimentadas de tumbas y toda su superficie era un auténtico cementerio. En su interior, los difuntos eran enterrados bien en fosas propias de su parentela (cada familia aspiraba a tener su tumba propia y su ubicación estaba en relación con su capacidad económica y posición social), bien en fosas comunes o bien en fosas propias de cofradías, hermandades o gremios. En lo que respecta al clero parroquial y a las distintas comunidades religiosas, disponían de un osario en un lugar destacado, casi siempre cerca del presbiterio o en torno al altar mayor del templo ${ }^{15}$.

Sin embargo, el crecimiento poblacional experimentado a lo largo de la centuria ilustrada, y el consiguiente incremento de las defunciones, llevó a que en muchas iglesias se plantearan problemas de espacio; los templos se quedaban pequeños para dar cabida a todos los difuntos de una parroquia ${ }^{16}$. Y no sólo era problema de espacio, también de salubridad. El continuo movimiento de cadáveres impedía que las losas que cubrían los enterramientos pudieran cimentarse correctamente, con lo cual la exhalación de malos olores se hacía casi constante; un hecho que se veía intensificado en los casos en los que el piso de la iglesia era de tablas de madera.

11 Juan Madariaga Orbea, "Espacio doméstico y espacio sepulcral...”, en Imízcoz Beunza, José María (ed.), Casa, familia y sociedad..., pp. 438 y 440-441.

12 Mercedes GRANJEL y Antonio CARRERAS PANCHÓN, "Extremadura y el debate sobre la creación de cementerios: un problema de salud pública en la Ilustración”, Norba. Revista de Historia, 17 (2004), pp. 76-78.

13 El espacio cementerial anexo a los templos también recibiría los restos humanos procedentes del vaciado de los nichos del interior. Esto, en teoría, ocurría años después de la muerte, y facilitaba el que otros cuerpos pudiesen también ser enterrados en las iglesias; ya que de no procederse en este sentido, éstas en pocos años hubieran estado totalmente colapsadas de enterrorios.

14 Fernando Martínez Gil, Muerte y sociedad en la ..., pp. 435-436.

15 José Luis SANTONJA, "La construcción de cementerios extramuros: un aspecto de la lucha contra la mortalidad en el Antiguo Régimen”, Revista de Historia Moderna, 17 (1998-1999), p. 38.

16 Ciertamente existían, desde hacía muchos años, mecanismos correctores para evitar la masificación; pero ahora se mostraban insuficientes. Los particulares podían ceder el derecho de sepultura o traspasarlo si no pensaban hacer uso de él, algo que también podía hacer el clero. El medio para establecer nuevas familias era la incautación de las tumbas que habían caído en desuso. Para certificar esta situación en cada festividad de Todos los Santos el sacristán recorría, acompañado de un notario, todo el templo certificando las sepulturas que estaban iluminadas y las que no. Cuando transcurrían tres años consecutivos en que se apreciaba la falta de cuidado en una sepultura se procedía a incautarla, vaciarla y establecerla a otro beneficiario (José Luis SANTONJA, "La construcción de cementerios...", Revista de Historia Moderna, 17 (1998-1999), p. 39.). 
Unas condiciones de insalubridad que se agravaban durante el período estival, al acelerarse los procesos de descomposición de los cadáveres. Es más, en muchas ocasiones, sobre todo en las ciudades, ni siquiera se observaban ciertas precauciones como la profundidad de las fosas, el uso de cal viva o la prohibición de la reapertura hasta que hubiera pasado cierto tiempo. Y, como consecuencia, los templos solían ser lugares infectos y malolientes ${ }^{17}$.

Pero a esta insalubridad de las iglesias contribuían también otros elementos, como las grandes cantidades de cera que se quemaban, la escasa ventilación, la humedad o el hacinamiento de fieles en los oficios religiosos. Del mismo modo, no menos malsano eran las mondas, un proceso de limpieza que periódicamente se practicaba en las sepulturas a fin de sacar los restos y dejar libres los enterramientos para que pudieran ser nuevamente utilizados. Los restos de estas operaciones se trasladaban a los osarios y fosas del cementerio exterior ${ }^{18}$; y mientras duraba, las iglesias quedaban totalmente inutilizadas, viéndose sus cercanías inundadas de los malos olores que desprendían los enterramientos ${ }^{19}$.

\subsection{Coexistir con los muertos (siglos XVIII y XIX)}

Ahora bien, una situación que se había mantenido durante siglos sin que los ya mencionados malos olores fueran motivo para trastocar el orden tradicional de las cosas, empezó a ser objeto de denuncias ${ }^{20}$ y en la segunda mitad del siglo XVIII se desplegó en Europa una auténtica campaña de opinión proclive a la construcción de cementerios fuera de las ciudades.

Factores muy diversos influyeron en este cambio de mentalidad, perceptible en un primer momento sólo en las minorías ilustradas. Las razones médicas, a pesar de ser fundamentales, no fueron las únicas. Parece ser que la difusión de la doctrina miasmática y el desarrollo de la química neumática contribuyeron a crear un lenguaje olfatorio y a otorgar mayor relevancia social a este sentido. A la par, los primeros pasos hacia la secularización de la sociedad dados en este siglo condujeron a una mayor valoración de la vida terrena, del aquí y ahora frente a una hipotética existencia postmortem ${ }^{21}$.

En este siglo, los habitantes que residían cerca de las iglesias y de los cementerios parroquiales comenzaron a quejarse, a redactar instancias. Hubo prestigiosos médicos y químicos que publicaron a la par sus reflexiones sobre los peligros mortales de los entierros en las iglesias. Por su parte, magistrados y eclesiásticos ilustrados contribuían al debate demostrando que el entierro en las iglesias se oponía tanto al derecho romano como al canónico, y que no era sino un efecto tardío de las supersticiones medievales.

Todo ello llevaría, por ejemplo, en la temprana fecha de 1763, a que la Corte del Parlamento de Francia ordenase una investigación sobre el estado de los cementerios parisinos con objeto de trasladarlos fuera de la ciudad. Hecho que tendría lugar durante dos inviernos consecutivos, de

17 Mercedes GRANJEL y Antonio CARRERAS PANCHÓN, "Extremadura y el debate sobre la creación...”, Norba. Revista de Historia, 17 (2004), pp. 76-78.

18 Hasta el siglo XVIII, los restos humanos se distribuían tanto en el interior como en el exterior de las parroquias. Los patios anexos a éstas les servían de cementerio. Es más, no era inusual la existencia de galerías exteriores en las que se disponían huesos, calaveras y otros miembros. Éstos procedían esencialmente de las grandes fosas comunes, que cuando se llenaban a tope, eran cerradas, procediendo a la apertura y vaciado de otra anterior.

19 Mercedes GRANJEL y Antonio CARRERAS PANCHÓN, "Extremadura y el debate sobre la creación...", Norba Revista de Historia, 17 (2004), p. 78.

20 Con precedentes tan destacados, ya en el siglo XVI, como Lutero. En 1527, éste, con ocasión de la peste de Wittenberg, defendería la idea de cementerio al estilo romano, alejado de las ciudades; lugar apartado y favorable al recogimiento.

21 Mercedes GRANJEL y Antonio CARRERAS PANCHÓN, "Extremadura y el debate sobre la creación...", Norba. Revista de Historia, 17 (2004), pp. 76-78. 
1785 a 1787; destacando la desmantelación del antiguo cementerio de los Inocentes, de donde se sacaron "más de 10 pies de tierra infectada de despojos de cadáver", y asimismo se "abrieron 40 o 50 fosas comunes exhumando más de 20.000 cadáveres con sus ataúdes"22.

Esta iniciativa, a la que se sucederían muchas otras en las décadas siguientes, nos habla de un indicio importante de cambio de mentalidades. Ahora bien, los restos humanos fueron acarreados de noche, a la luz de antorchas y braseros, y en presencia de sacerdotes, para atenuar en la medida de lo posible el malestar que a muchos provocaba esta medida.

\section{LA PRESENCIA FÍSICA DE LA MUERTE EN LA CÓRDOBA DEL ANTIGUO RÉGIMEN}

Ciertamente contamos en la actualidad con muy pocos datos que nos informen acerca de la presencia física de la muerte en el reino de Córdoba entre los siglos XVI y XIX, pues los estudios realizados, especialmente los de la profesora María Soledad Gómez Navarro, se centran en la muerte desde el punto de vista metafísico. Conocemos relativamente bien la experiencia de la muerte, el ritual postmortem y los cuidados espirituales del finado (todo lo relativo a su alma), pero no se nos informa de lo que ocurre con su cuerpo; en definitiva, de la "herencia corporal" que deja a sus congéneres.

En cualquier caso, intentaremos ofrecer algunas pinceladas del tema que nos ocupa para el caso cordobés.

\subsection{Vivos y muertos en los siglos XVI y XVII: una estrecha convivencia}

Los edificios religiosos del reino de Córdoba participaron también del proceso de conquista de los recintos eclesiásticos por parte de los enterramientos de los fieles. Una realidad tan intensa que incluso en nuestros días podemos apreciar aún numerosas lápidas en muchas iglesias. Por lo cual, estos recintos tampoco serían ajenos a la problemática higiénica y olfativa que esta práctica conllevaba.

En este sentido, podemos mencionar, a modo de ejemplo, un caso ocurrido en 1785 en la ciudad de Córdoba. En aquella fecha, debido a una epidemia de fiebres intermitentes (dolencia tras la que se oculta el paludismo), fue preciso cerrar al culto la iglesia de Santa Marina de Aguas Santas, pues "fueron tantos los cadáveres en ella sepultados, que empezaron a exhalar tantos miasmas que se creyó perjudicarían a la salud pública"23.

\subsection{El triunfo de la higiene en los siglos XVIII y XIX: un espacio alejado para los difuntos}

A pesar de que se contaba con antecedentes tan interesantes como las quejas elevadas por los feligreses de Montilla acerca del olor insoportable de su iglesia, que llevaron al duque de Medinaceli, en 1709, a ordenar que durante un año los entierros se realizasen en las ermitas de la ciudad para descongestionar la parroquia, la verdad es que para el caso del reino de Córdoba, el punto de inflexión fundamental para la construcción de cementerios lo constituyeron las epidemias de fiebre amarilla de 1800-1801 y 1803. Sólo entonces parece

Philippe ARIÉS, La muerte en Occidente..., pp. 124-125

23 Teodomiro RAMÍREZ DE ARELLANO Y GUTIÉRREZ, Paseos por Córdoba, o sea apuntes para su historia, León, 1995 , p. 85. 
que se tomó en serio el grave problema sanitario que suponía el mantener dentro de los recintos urbanos las áreas de enterramiento ${ }^{24}$.

Cronológicamente, el período de aplicación de normativas sobre edificación de cementerios para el ámbito cordobés arranca en 1787. Sin embargo, este reino contaba con un interesantísimo precedente de erección, en $1769^{25}$, de un cementerio en un lugar sano, elevado, ventilado y suficientemente alejado del casco urbano como para no provocar problemas de salubridad. Se trataba del camposanto de la colonia de La Carlota ${ }^{26}$, localidad fundada a mediados de 1768 bajo unos presupuestos ilustrados.

Casi dos décadas antes de la Real Cédula de 1787, en esta nueva población nos encontramos con que sólo se permitían los entierros en su cementerio. Un hecho que, en principio, podría llevarnos a pensar en un posible malestar entre los fieles; sin embargo, el análisis de sus disposiciones testamentarias nos muestra, curiosamente, desde un primer momento el deseo de todos los colonos de ser enterrados en el cementerio, y ello a pesar de no existir ninguna capilla en su interior o a sus proximidades ${ }^{27}$.

Por otro lado, en lo que respecta a las disposiciones de la mencionada Real Cédula de $1787^{28}$, sólo una localidad cordobesa se animará a cumplirlas inmediatamente. El 25 de junio de 1787 se pide en Baena el establecimiento de un cementerio público ventilado para restituir el debido culto en las iglesias, con lo que desaparecería el recelo de los fieles a acudir a la iglesia tras la epidemia de paludismo que acababan de padecer $^{29}$.

En 1801 le tocó el turno a la villa de La Puente de Don Gonzalo, donde fueron los mismos vecinos los que tomaron la iniciativa de construir un cementerio donde poder sepultar los cadáveres de los que murieran a partir de entonces y que, además, sirviese para depositar los restos que se sacasen de las sepulturas de la iglesia ${ }^{30}$.

En el caso de El Carpio, ante el reducido tamaño del tempo parroquial, será el propio párroco quien decida iniciar, en 1804, las gestiones para construir un camposanto; animado sobre todo por la epidemia de fiebre amarilla que entonces se cernía sobre buena parte de Andalucía. Sin embargo, en 1806 todavía no se había iniciado la inspección de los terrenos, el examen del médico y el dictamen del arquitecto ${ }^{31}$.

En 1805, Palencia, villa dependiente de la jurisdicción del marqués de Benamejí, obtendrá licencia para erigir en su término un cementerio, con arreglo a lo prevenido en las reales órdenes. Por último, en Montilla no se acometerá de forma decisiva la construcción del camposanto definitivo en los terrenos aledaños a la ermita de la Vera Cruz hasta 1816.

24 María Soledad Gómez Navarro, "La construcción de cementerios en la provincia de Córdoba (1787-1833)", en Una arquitectura para la muerte. Actas del I Encuentro Internacional sobre los cementerios contemporáneos, Sevilla, 1993 , p. 400.

25 Archivo General del Obispado de Córdoba, Nuevas Poblaciones, “Correspondencia de D. Joseph Lázaro Sánchez Rubio, Presbítero, Vicario y Cura $1^{\circ}$ de La Carlota, 1769-1770-1771".

26 Para no faltar a la verdad, La Carlota no se encontraba dentro del reino de Córdoba. En su establecimiento se había utilizado parte de su territorio, pero junto a las restantes Nuevas Poblaciones conformaba una realidad política y administrativa diferente; no así eclesiástica, pues pertenecía al Obispado de Córdoba.

27 Archivo Parroquial de La Carlota, Testimonios de Colecturía, legs. 1 y 2. Desconocemos cuáles fueron las razones que llevaron a los habitantes de esta colonia a aceptar tan fácilmente su entierro en un cementerio alejado de la parroquia, sin embargo puede que algo tenga que ver la heterogénea procedencia de los colonos y el hecho de que el templo parroquial no puede alojar tumbas en su suelo (bajo él se sitúa una falsa cripta, resultado de haber salvado un desnivel del terreno).

28 Grosso modo, esta disposición normativa mandaba erigir camposantos cuanto antes fuera de todas las poblaciones y prohibía los entierros dentro de las iglesias (Máximo GARCÍA FERNÁNDEZ, Los castellanos y la muerte. Religiosidad y comportamientos colectivos en el Antiguo Régimen, Valladolid, 1996, pp. 233-234).

29 Archivo Municipal de Córdoba, sección 9, subsección 6, serie 1, caja 869, doc. 1.

$30 \quad$ Ibíd., caja 869 , doc. 8.

31 María Soledad Gómez Navarro, "La construcción de cementerios en...", en Una arquitectura para la muerte ...,pp. 400-401 . 
Finalmente, nos queda el caso de la ciudad de Córdoba. El 5 de enero de 1805 se reconocieron las zonas más adecuadas para la construcción de cementerios permanentes, concluyendo los inspectores que no había terrenos mejores que los mismos en que se hallaban ya los tres provisionales establecidos un año antes: uno, en las proximidades del camino que iba a la hacienda del Arenal, por detrás del convento de San Juan de Dios; otro, a espaldas de la huerta de la Reina; y el tercero, en el pago de la Salud.

Pero las incidencias políticas de la Guerra de la Independencia perturbaron el ritmo de las obras en el caso concreto del cementerio de La Salud, cuya construcción quedó interrumpida transitoriamente en 1808; se reanudaron las tareas en octubre de 1810, y se suspendieron de nuevo a mediados de 1811. Por ello, no será hasta 1833 cuando se inaugure completamente terminado ${ }^{32}$.

Una vez finalizado este rápido repaso sobre la evolución cronológica y geográfica en algunos lugares de la provincia de Córdoba que se aprestaron con mayor o menor rapidez a aplicar los criterios ilustrados de la edificación de cementerios extramuros, nos resta sólo plantear, aunque sea concisamente, el sintomático clima de contestación social, positiva o negativa, que tal actuación generará.

Desde fines del Setecientos se aprecia con claridad un cambio en la elección del destino final del cuerpo muerto, que va de la iglesia al cementerio extramuros. Según la profesora Gómez Navarro, para el caso del reino de Córdoba, la petición testamentaria de ser enterrado en el cementerio sólo supone un $2,71 \%$ de la muestra por ella analizada. Ahora bien, se aprecia un incremento desde fines del siglo XVIII y sobre todo desde comienzos del XIX, y de forma muy contundente sobre todo en el área rural. Así, para el caso de Montilla se alcanza en 1820 el $93,75 \%$ de las demandas ${ }^{33 i}$. Sin embargo, este cambio mental no fue fácil; en Baena, ni un solo testador entre 1789 y 1791 hizo referencia en su última voluntad al cementerio, prueba de lo arraigado que continuó el deseo de ser enterrado en el interior de los templos ${ }^{34}$.

\section{CONCLUSIONES}

Una vez expuestas las principales características acerca de la percepción social de la muerte física durante la Edad Moderna, pasaremos a continuación a recapitular algunas de las ideas más destacadas.

Básicamente, podemos distinguir dos fases: la primera, que abarcaría los siglos XVI y XVII, se caracterizaría por lo que podríamos denominar como la conquista de los templos; un periodo en el que la muerte y su espacio y elementos físicos pasan a ser manejados por la jerarquía eclesiástica. Por su parte, la segunda fase, iniciada ya en el siglo XVIII, podría definirse como un exilio de los muertos o, dicho de otro modo, por un alejamiento del espacio de los muertos de las áreas cotidianas de los vivos.

$\mathrm{Al}$ iniciarse, a comienzos del siglo XVI, la fase de sepulturización democrática, por la que el conjunto de la comunidad -frente a lo que ocurría en la Baja Edad Media, en que sólo los individuos más destacados de la sociedad podían disfrutar de un entierro intraeclesiástico, debiendo los demás conformarse con un lugar en el cementerio anexo al templo- pasó a inhumarse

$32 \quad$ Ibíd.,pp. 401-402.

33 María Soledad Gómez Navarro, Una elaboración cultural de la experiencia del morir. Córdoba y su provincia en el Antiguo Régimen, Córdoba, 1998, pp. 140-141.

34 Archivo Histórico Provincial de Córdoba, Protocolos de Baena: oficio 1, legs. 531P (1789), 532P (1790), 533P (1791); oficio 2, leg. 567P (1789-1791); oficio 3, leg. 567P (1789-1791); oficio 4, leg. 548P (1789-1791); oficio 5 , legs. 558P (1789-1790) y 1559P (1791); oficio 6, legs. 514P (1790) y 515P (1791); y oficio 7, legs. 565P (1789) y $566 \mathrm{P}(1790-1791)$. 
al interior de las iglesias, surgieron varios problemas; uno, bastante común, el de la incapacidad física del templo para acoger sepulturas de todos los vecinos (a la que hemos de sumar el potencial riesgo para la salud de los individuos que acudían a estas iglesias), situación que se agravaría con el significativo aumento poblacional de la segunda mitad del siglo XVIII.

Por otra parte, el segundo problema sería la necesidad de disponer las sepulturas ordenada e igualitariamente, intentando que ninguna destacase ni por su tamaño, ni por su altura, ni por la colocación de elementos que la diferenciase de las demás. Una cuestión esta última que en la práctica nunca fue de la mano de la teoría. El espacio sepultural intraeclesiástico se estableció de facto de acuerdo a una estricta jerarquización socioeconómica. Una circunstancia que, entre otras muchas, sería esgrimida por los sectores sociales más elevados para oponerse a la creación de cementerios extramuros a partir de finales de la centuria ilustrada; pues en modo alguno estaban dispuestos a perder un espacio de escenificación y promoción social tan concurrido como eran las iglesias.

En otro orden de cosas, el vínculo que unía a los vivos y a los muertos en este momento histórico era aún muy fuerte; pues la creencia en un sistema de protección recíproca que vinculaba a los primeros con los segundos mediante misas y plegarias a cambio de protección e intercesión estaba muy presente en el imaginario colectivo. No obstante, las medidas higienistas comenzaron a imponerse (sobre todo a través de disposiciones normativas), dando paso a un largo periodo de tránsito en el que la sociedad fue gradualmente aceptando el cambio que se le imponía. Por tanto, a pesar de las resistencias de la comunidad, se acabaría asimilando la necesidad de separar a los vivos de los muertos.

\section{APÉNDICE DOCUMENTAL}

\section{Testimonios sobre la falta de salubridad en el interior de los templos durante la Edad Moderna}

1. «La atmósfera es por lo regular húmeda y pesada en los templos, cuyas calidades adquiere con los efluvios de las personas que en ellos concurren; la mezcla de las exhalaciones sepulcrales, que forzosamente calan la tierra que cubre los muertos, no puede menos de ser funesta en un paraje donde todo conspira a reconcentrar los vapores dañosos» ${ }^{35}$.

2. «En un hoyo que hacen los sepultureros, que por lo regular apenas llega á la profundidad de dos varas, por lo menos se entierran quatro cadáveres con especialidad en las Parroquias grandes, y de mucha feligresía. El espacio que corresponde á cada uno de ellos es una quarta de vara, á parte más y a parte menos, y á proporción de los cuerpos, quedando el espacio de las otras quatro cuartas de vara para la tierra que los encubre. Como se observó públicamente en la descavación del pavimento de la Parroquial de Santa Cruz en ocasión de su reedificación por el incendio que padeció. En el qual pavimento se vio que los cadáveres están tan someros que de la superficie de el pavimento á la de los cadáveres no había la expresada cuarta de tierra que los encubría. Corrompiéndose luego esta tierra por el contacto de la corrupción de las substancias de los cadáveres, es muy manifiesto que se forma un cuerpo corrompido más abultado. Supuesto el expresado aumento, ¿quien negará que se aumentan las exudaciones, ya en su número como en la duración?» ${ }^{36}$.

35 Testimonio del médico francés Vicq d'Azyr sobre el interior de los templos parroquiales franceses en el siglo XVIII (Enrique Giménez López, "La exhalación de la muerte. La aportación del matemático Benito Bails a la polémica sobre los cementerios en el siglo XVIII", Revista de Historia Moderna, 17 (1998-1999), p. 139)

36 F. BRUNO FERNÁNDEZ, Disertación fisico-legal de los sitios, y parages, que se deven destinar para las sepulturas: que dedica a los interesados de la salud pública, verdaderos amigos de la patria, Madrid, 1783, pp. 53-54. Tomado de Mercedes GRANJEL y Antonio CARRERAS PANCHÓN, "Extremadura y el debate sobre...", Norba. Revista de Historia, 17 (2004), p. 77. 
3. «Es indubitable que en muchas de las Iglesias de nuestra Diócesis [Valencia] se hace insufrible el mal olor que despiden los cadáveres, lo que retrae á muchas gentes de la concurrencia á sus Parroquias, y les precisa irse á otros templos en los que no son tan freqüentes los entierros» ${ }^{37}$.

4. «[La iglesia parroquial de El Carpio era muy pequeña] y no bastante para contener los cadáveres, [...] por lo que llenas las sepulturas de la iglesia y exhalando malos olores, que causan flatos, mareos, arcadas y males de estómago, [las gentes se retraen de ir a misa]» ${ }^{38}$.

\section{Testimonios relativos a fallecimientos derivados del exceso de entierros en las iglesias}

1. «En León de Francia sucedió que habiendo puesto en una bóveda un difunto sin cubrir de tierra, de allí a pocos días le abrieron para depositar otro y queriendo entrar dentro de ella el sepulturero salió tan pestilencial hedor que, no pudiendo sufrirle el hombre, quedó muerto ${ }^{39}$.

2. «Un caluroso día de agosto de 1744, un sepulturero se desplomó al abrir un sepulcro de los penitentes blancos de Montpellier para depositar el cuerpo de un cofrade difunto. "No bien hubo bajado al hoyo, vieron cómo se agitaba víctima de convulsiones". El hermano penitente que intentó auxiliarle escapó por muy poco al peligro: "Mandó que otro hermano penitente le sujetara por la punta de la sotana y del cordón, y se descolgó. No había hecho más que agarrar las ropas del sepulturero cuando perdió la respiración. Lo sacaron medio muerto. Al poco rato recuperó el sentido, pero le quedó una especie de vértigo y aturdimiento, precursores de convulsiones y desmayos que habrían de manifestarse un cuarto de hora después". Por suerte, sus mareos "desaparecieron gracias a una sangría y a algunos cordiales". Sin embargo, "estuvo mucho tiempo pálido y desfigurado, y desde entonces en el pueblo le llamaron el resucitado". Otros dos penitentes intentaron salvar al infeliz sepulturero que seguía en el hoyo, inanimado. El primero, "sintiendo que se asfixiaba" tuvo tiempo de hacer gestos para que lo sacaran. El segundo, más robusto, cayó víctima de su fuerza y su audacia: "murió casi al instante de haber bajado”. Luego le tocó morir al hermano del sepulturero, el último de esta catastrófica serie; pues entonces quedó claro el riesgo y ya no hubo nadie que quisiera exponerse a una nueva tentativa, a pesar de los "acuciantes exhortos" del clero»"

3. «El domingo por la tarde sucedió en Nuestra Señora de Loreto [Madrid] una cosa rara. Abrieron una bóveda para enterrar un niño. Asomóse el sepulturero a la boca para entrar y se quedó medio muerto. Llegó un doctor, haciendo de piernas, y a dos pasos que dio perdió el juicio; y acudiendo otra vez el sepulturero a sacarle, murieron los dos; sin que nadie osase a llegar más. Metieron un hacha de cuatro pabilos encendida, siendo lo mismo que meterla en agua. Hanla cerrado a cal y canto. Dícese que el aire estaba tan craso que les tapó la respiración; y porque no saliese alguna corrupción, la han tapado» ${ }^{41}$.

37 Fray Joaquín Company (Arzobispo de Valencia), A todos nuestros Curas Párrocos y demás Diocesanos, 1806. Tomado de Santonja, José Luis, "La construcción de cementerios extramuros...", Revista de Historia Moderna, 17 (19981999), p. 33.

38 María Soledad Gómez Navarro, "La construcción de cementerios en...”, en Una arquitectura para la muerte..., p. 401.

39 Fernando Martínez Gil, Muerte y sociedad en la..., p. 444.

40 Philippe Aries, La muerte en Occidente..., pp. 104-105.

41 Fernando Martínez Gil, Muerte y sociedad en la..., p. 444. 